\title{
VIVIR CON DOLOR DE MIEMBRO FANTASMA: PERSONA POSTAMPUTADA
}

\section{LIVING WITH MEMBER PHANTOM PAIN: PERSON POSTAMPUTADA}

Recibido 18 de noviembre 2014 Aceptado 31 de enero 2015

Correspondencia: Ma. Cristina Ochoa Estrada Número de Celular: 6181891301 cristy8@ujed.mx,cristys8@hotmail.com

\section{Autores:}

Ma. Cristina Ochoa-Estrada

Doctora en Ciencias de Enfermería. Profesora de tiempo completo. Facultad de Enfermería y Obstetricia.

Universidad Juárez del Estado de Durango. Enfermera Quirúrgica adscrita al Hospital General 450. Durango, México.

Sebastián Bustamante-Edquen

Doctor en Enfermería de la UFRJ-Brasil. Profesor principal de la Facultad de Enfermería. Universidad Nacional de Trujillo, Perú.

Carlos Hernández-Peraza

Maestro en Ciencias Médicas. Médico Anestesiólogo adscrito al Hospital General 450. Durango, México.

Palabras clave: Vivir con dolor, dolor de miembro fantasma (DMF), persona posamputada.

Key Words: Living with pain, phantom limb pain (DMF), posamputada person 
RESUMEN

Objetivo: Describir el vivir con dolor de miembro fantasma en la persona posamputada.

Método: Estudio de abordaje cuallitativo-descriptivo, exploratorio; y como técnica se empleó la entrevista semiestructurada, los sujetos participantes residen en el Estado de Durango, México; participaron 12 personas que al ser amputadas debutaron con Dolor de miembro fantasma, el soporte teórico estuvo apoyado con el dolor de Le Breton (1999) $)^{21}$

Resultados: En los discursos de la persona posamputada se evidencían expresiones de una vida sin objetivos, se de terminan a desempeñar el rol de enfermos al considerar su dolor como una tragedia personal o una desviación social que enluta su vida y la de su familia.

Consideraciones Finales: La enfermera debe aprender a escuchar el cuerpo enfermo, seguir con atención sus señales y sus expresiones ya sean de alegría, llanto, tristeza, dolor, desagrado, silencio, etc., interpretando lo que trata de comunicar y solicita. Deberá estar atenta y vigilante procurando que el cuerpo-sujeto alivie el dolor físico y el dolor del alma, que se pueda revertir permanente por el resto de su vida, pues vivir con dolor desde el punto de vista fisiopatológico constituye una crisis circunstancial, eventual y controlable que no sucede igual con la enfermedad del alma.

Palabras claves: Vivir con dolor, Dolor de miembro fantasma (DMF), persona posamputada.

\section{ABSTRACT}

Objective: To describe the live with phantom limb pain in posamputada person.

Method: Qualitative Study-descriptive, exploratory approach; and as a semi-structured interview technique was employed, participating subjects residing in the State of Durango, Mexico; involving 12 people to be amputated debuted with pain phantom limb the theoretical support was supported with the pain of Le Breton (1999) ${ }^{21}$

Results: In the discourses of posamputada individual expressions of life without goals is evident, are determined to play the role of patients to consider their pain as a personal tragedy or social deviance that his life and mourns for his family.

Final Thoughts: The nurse must learn to listen to the sick body, carefully follow their signals and whether their expressions of joy, sorrow, sadness, pain, disgust, silence, etc; interpreting what is communicating and requests. You must be alert and vigilant care that the body-subject relieve physical pain and the pain of the soul, which can be reversed permanently for the rest of your life, because living with pain from the physiological point of view is a circumstantial eventual crisis and controllable which does not happen with the disease of the soul.

Keywords: Living with pain, phantom limb pain (DMF), posamputada person. 


\section{INTRODUCCIÓN}

$\bigvee$

Ivir es el conjunto de las cualidades fundamentales propias de la existencia de los seres auto-(geno-feno-ego)-eco-reorganizadores; todo ser viviente-es decir, todo individuo-sujeto comenzando por el unicelular, dispone de las cualidades fundamentales de la vida; pero estas cualidades han evolucionado y se han desarrollado. El unicelular que se reproduce por duplicación no nace realmente, vive en régimen reducido, sólo muere in extremis. El unicelular surgido de una reproducción sexuada comienza a nacer. El espermatozoide y el óvulo que se fusionan mueren a medias al producir un nacimiento. Son los animales superiores los que han desarrollado no sólo la organización viviente, sino el vivir. Se vive más intensamente cuando se está dotado de un aparato neurocerebral rico y activo, es decir, dotado de sensibilidad, de afectividad y de inteligencia. Nacer, existir y morir adquieren su sentido pleno y fuerte en los altos desarrollos de la vida.

Vivir es sentir, experimentar, autopercibirse y descubrir las relaciones humanas que sostienen nuestra existencia e intervenir en ellas con la voluntad de aportar nuestra novedad. Es prestar atención al llanto y a la risa, permanecer en silencio junto al que sufre, alegrarse con quien goza, es valorar a los demás por lo que son, no por lo que tienen; por su valor, no por su eficacia. Vivir es darnos cuenta de los aspectos de verdad que capta nuestra inteligencia para ensancharlos en el diálogo con los demás. Vivir es gozar de las cosas pequeñas, de las personas cercanas que nos entregan su afecto, de la naturaleza y la relación con los demás en el entorno. Al respecto Maturana² manifiesta que la vida no tiene sentido fuera de sí misma, y que el sentido de la vida de un ser humano es el vivir humano al ser humano en el humanizar.

En el vivir cotidiano de la persona, el impacto de una amputación es enorme, por la falta de funcionalidad, la reintegración social y prolongada expectativa de vida que es posible lograr en este grupo de personas; entendiendo por amputación como la pérdida de forma traumática o quirúrgica, de una estructura anatómica del cuerpo, y que es más prevalente en las extremidades, sin que se excluya otros órganos. ${ }^{3}$

Las personas amputadas de manera inesperada (traumática), conforman un grupo especial dentro de todo el universo de las personas que han sufrido amputación de otros orígenes, especialmente los de accidentes de tránsito, actos violentos y accidentes laborales, que son las más frecuentes a nivel poblacional. La pérdida de una parte del cuerpo va seguida de un proceso psicosocial de aceptación y adaptación cuyo resultado va a depender de múltiples variables. ${ }^{4}$

La Organización Mundial de la Salud (OMS) estima que actualmente el 10\% de la población del mundo, esto es aproximadamente 650 millones de personas, padecen algún tipo de discapacidad intelectual, física o sensorial. Se estima que, además, el número de personas con discapacidad está aumentando debido al crecimiento mismo de la población, al incremento en la esperanza de vida y en consecuencia al progreso de envejecimiento que hoy en día enfrenta la población mundial. ${ }^{5}$

La discapacidad motriz es la más frecuente, tanto en localidades urbanas como rurales, pero la prevalencia es más alta en el área urbana y afecta más a las mujeres. Son diversas las causas que originan una discapacidad, pero las más relevantes están asociadas a factores genéticos, enfermedades agudas o crónicas, violencia, accidentes, sedentarismo, complicaciones perinatales, traumatismos, problemas nutricionales y características del entorno físico, entre otros. Diversos estudios han demostrado que en las regiones desarrolladas, los accidentes automovilísticos, y la mayor longevidad son los factores que han propiciado un incremento en la prevalencia de discapacidad, mientras que en las regiones menos desarrolladas, las principales causas son la malnutrición, el alcoholismo, la 
drogadicción, violencia, así como la poca accesibilidad a servicios de salud, entre otros. ${ }^{5}$

En la República Mexicana existen 112, 336, 538 habitantes, de éstos 5, 739, 270 presentan discapacidad entre las cuales se destaca la dificultad para moverse y caminar, el cual corresponde a $58.3 \%$. Mientras que en el estado de Durango, México; existen 1, 632, 934 habitantes de los cuales 96, 587 presentan discapacidad motriz, el cual corresponde a un $62 \%$.

El dolor de miembro fantasma (DMF) se refiere a la presencia de sensaciones dolorosas en una extremidad ausente y se clasifica como un dolor de origen neuropático. ${ }^{7.8}$ Ambroise Paré, cirujano francés, fue el primero en notar en el año de 1552 que los pacientes se quejaban de dolor severo después de la amputación de una extremidad, postulando que factores periféricos y centrales participaban en la generación de dicha sensación. Siglos después (1872), Silas Weir Mitchell acuñó el término "dolor de miembro fantasma» para caracterizar esta entidad.9.10,1,12 La incidencia varía desde el 2 al 80\%, independientemente de la etiología. 8,9,10 Tales diferencias en la incidencia reportada por diversos estudios son debidos a la falta de una definición unificada para el DMF, o que en muchos casos los pacientes no reportan el dolor por temor a ser estigmatizados como enfermos mentales. ${ }^{7.93} \mathrm{La}$ incidencia del dolor fantasma parece ser independiente del género, del nivel de la amputación y de la edad en adultos. A pesar de lo anterior, el dolor fantasma continúa siendo menos frecuente en niños y jóvenes y prácticamente no existe en sujetos nacidos sin una extremidad. ${ }^{78,74}$

De esta manera, el dolor de miembro fantasma en la persona postamputada cumple una función vital como símbolo de alarma, al convertirse en enfermedad misma, el dolor irrumpe en la cotidianidad de la persona, trastoca y trasforma la vida misma, no sólo de la persona afectada sino de su entorno social en general. El dolor involucra al sufrimiento, pudiendo ser, un motor de trasformación y creatividad y un lenguaje metafórico de la vida vivida. El dolor se vive como un castigo, una experiencia desagradable, una costumbre ritual, un acto de fe, como una posesión y una estrategia de control, una forma de vida de múltiples y problemáticas acciones sociales e individuales, manifestado por emociones frustrantes; el dolor es el reflejo de la frenética vida contemporánea enmarcada en la desmesura del consumo y el deseo de la salud, el dolor le recuerda a la persona postamputada que está vivo.

En el área de enfermería se evidencia la escasa investigación en torno al dolor de miembro fantasma, considerando este particular como una oportunidad para el desarrollo de procesos de intervención que profundicen en las causas que expliquen esta situación en la persona con amputación, que ayuden a revertir los obstáculos para este reconocimiento desde las políticas públicas y las consecuencias negativas que de ello se derivan; considerando la afección que tienen las personas con amputación y el resto de los miembros de su familia, impidiendo una integración plena en todos los aspectos del cotidiano de la persona. Por ello es el interés que esta investigación puede generar como apoyo en el quehacer del profesional de salud.

\section{REFERENCIAL METODOLÓGICO}

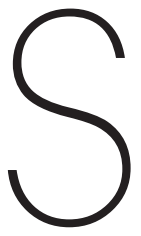
e optó por la investigación cualitativa con abordaje descriptivo-exploratorio.15,16 El escenario de estudio fueron los hogares de las personas postamputadas portadoras de dolor de miembro fantasma. Los informantes seleccionados fueron personas que se atendieron en el Hospital General de Durango, México. El número total de participantes se estableció al alcanzar el punto de saturación de la información con los discursos de doce personas. ${ }^{17}$

Los criterios de inclusión de los informantes claves, fueron: Personas que presentaban o manifestaban la patología de dolor de miembro fantasma, con amputación en miembros inferiores y supe- 
riores; amputación supracondilea, infracondilea, y transmetatarsiana, género masculino y femenino, personas con amputación de miembro de un lapso no mayor de 2 años, edades de 18 a 35 años de edad, no estar en periodo de embarazo - lactancia y personas sin deterioro cognitivo, sin patologías ni tratamiento psiquiátricos.

Como técnica de recolección de la información se utilizó la entrevista semiestructurada: ${ }^{18}$ elaborada por los autores y aplicada a los actores sociales participantes en la investigación en sus realidades concretas; ésta se dividió en dos partes: la primera parte caracterizaba a los sujetos de la investigación, y en la segunda parte las preguntas fueron relacionadas con el objeto de estudio.

Obtenido el consentimiento informado, se coordinó con los participantes sobre el lugar, fecha y horario de las entrevistas. Las entrevistas se realizaron en el periodo de Abril a Agosto de 2011. Las entrevistas fueron grabadas en grabadora digital y posteriormente transcritas para el análisis e interpretación de las mismas, tomando como referencia los objetivos establecidos en la investigación.

Se procedió a realizar un análisis temático de la información el cual "consistió en descubrir núcleos de sentido que componen una comunicación cuya presencia o frecuencia significan alguna cosa para el objetivo visado", para lo cual importa más la expresión verbal y la comprensión simbólica de una realidad a ser conocida. ${ }^{19}$ Para la operacionalización del análisis se siguieron, básicamente, tres etapas: pre-análisis, exploración del material y tratamiento e interpretación de los resultados. ${ }^{19}$

Este estudio fue realizado con base en el reglamento de la Ley General de Salud en materia de Investigación, 20 relacionado con el desarrollo y validación de los aspectos éticos de las investigaciones con seres humanos, prevaleciendo los principios de respeto y la protección de sus derechos.

Con la finalidad de aumentar la calidad y objetividad de la información se consideraron los procedimientos propuestos por Hernández.16 A fin de in- crementar la posibilidad de los resultados a través del compromiso del investigador con el informante en el transcurso de la investigación y documentar la credibilidad se utilizaron las siguientes técnicas: cre dibilidad, transferibilidad, formalidad y confirmabilidad.

\section{RESULTADOS}

urante la dinámica, diversos elementos
relacionados al VIVIR CON DOLOR, fueron
debatidos. En este artículo se presenta
el análisis de las declaraciones de los
participantes.

El dolor de miembro fantasma en la persona postamputada no es más que un síntoma contingente, molesto, ruidoso, penoso, a menudo difícil de suprimir, pero que habitualmente le demuestra a la persona que tiene vida. Para Le Breton ${ }^{27}$ el dolor se distingue de un simple mensaje sensorial excesivo, ataca al hombre en su identidad y a veces lo quiebra; parece un sentido defensivo, útil, pero en la misma medida contumaz, bloqueado y mutilador, con frecuencia acaba por transformarse en la enfermedad que hay que tratar.

"(....... Mi vida es una vida sin sentido, sin salud, el dolor no es salud es enfermedad... sientes calor y frio es doloroso y duele algo que ya no existe en tu cuerpo". (P-05)

El participante se expresó sin un proyecto de vida, sin objetivos, todo ello por el dolor, un dolor que es invisible, oculto, fantasmal, sentido por cualquier persona que le ha ocurrido una contingencia de vida, siendo lo común la enfermedad del cuerpo, lo fantasmal, lo desconocido a lo que no es aparente, la opacidad. Es decir, la persona postamputada portadora de dolor de miembro fantasma, considera su dolor como una tragedia, una enfermedad personal o una desviación social que afecta su vida y la de su familia, se determina a desempeñar el rol de enfermo.

Mientras que en el siguiente discurso se confirmó la trayectoria que sigue el dolor de miembro fantasma, porque las personas en ningún momento están preparadas para afrontar efectivamente la

\section{2}

IMNVMYw Vol.14. No. 1 enero-abril 2015 
nueva condición de discapacidad y enfrentarse al cambio dentro de la sociedad, donde su intereses y modos de vida social surgidas por esta limitación adquirida viene a ser un obstáculo para desenvolverse socialmente, apoyando esto con lo que manifiesta Le Breton, ${ }^{21}$ cuando asegura que el dolor se sirve de puertas que lo ralentizan, amortiguan o aceleran su paso. Así otras percepciones sensoriales entran en resonancia con él y contribuyen a modelarlo (calor, frio masaje, etc.). Ciertas condiciones lo inhiben (concentración, relajación, diversión etc.). Otras aceleran su difusión y lo acrecientan (miedo, fatiga, etc.).

"(...) No se lo deseo a nadie, en un inicio era insoportable, creo que cada vez lo soporto menos, siento que me aplastan mi parte amputada, da comezón y me hormiguea bastante, me oprimen, me duele y desespero con ganas de llorar". (P-07)

En el discurso anterior la persona manifestó lo insoportable que le resulta vivir con el dolor, más cuando presenta signos como la comezón, el hormigueo, desesperación, entre otros que le hacen vivenciar su dolor en esa parte que no existe que lo hacen recordar que es una persona (in)completa.

El dolor de miembro fantasma se caracteriza por la sensación que experimenta la persona amputada y que consiste en seguir percibiendo la extremidad con un alto grado de realidad, tanto en sus componentes sensoriales como motores, apoyando esto con Fernández y Pellicer22,23 cuando mencionan la génesis del miembro fantasma como un proceso de alto grado de desarrollo cerebral; inclusive como parte de un proceso más general en el que intervienen las esferas cognoscitivas y afectivas. Argumentan que las experiencias corporales de un sujeto producen efectos sobre sus cogniciones, imaginación y memoria. Si esas sensaciones corporales se alteran, entonces se afecta el aprendizaje central y sus respectivos procesos de memoria, al punto de crear nuevas vías que comprometen la concepción de la conciencia corporal, apoyando esto con el siguiente discurso:
"(....... Me siento incómodo y más cuando duele, estoy cansado... me hormiguea y me da picazón caliente, molesta siempre, me encuentro desesperado con ganas de llorar, me pongo con rabia; quieres demostrar que no lo tienes pero tu cara y tu cuerpo te delatan" (P-01)

Evidenciándose, que la persona amputada manifiesta dolor en la mutilación misma, donde pendía su pierna, su brazo, aquella parte del cuerpo que ya no tiene, guarda en su memoria la presencia del dolor de miembro fantasma, el recordatorio presente de su falta; la descripción que realiza del dolor, indica justamente, lo fantasmal de la percepción de un dolor de un miembro corporal que no existe físicamente. Complementando lo anterior con Le Breton ${ }^{21}$ cuando menciona que no hay dolor sin sufrimiento, es decir sin significado efectivo que traduzca el desplazamiento de un fenómeno fisiológico al centro de la conciencia moral del individuo, al sentir el dolor se crea estigmas sociales por su nueva condición de discapacidad, se concibe como un problema, por la limitación y los signos que presenta, tal como lo manifestó la persona:

\section{"(...) Creo que yo soy el problema, más cuando no controlo el dolor, siento que me duele y me quema al mismo tiempo, cuando cam- biamos a frío acá, es cuando se pone más fuerte el dolor". (P-02)}

Las palabras "me duele y quema al mismo tiempo" junto a lo expresado por el participante (P-01), "me hormiguea y me da picazón caliente, molesta siempre" o expresiones que muestran más abajo "es como si tuvieras chile", dan evidencia que la persona que experimenta una amputación de algún miembro, al seguir percibiendo su extremidad con alto grado de realidad, tanto en sus componentes sensoriales como motores enfatiza lo fantasmal y lo amplificado en la experiencia de la persona.

En silencio la persona que ha sufrido una amputación experimenta sensaciones que emanan de la parte amputada del miembro, estas sensaciones son "fantasmas" dolorosas y provocan perturba- 
ciones, siendo éstas muy similares a aquellas que se sienten en un miembro intacto, incluyendo calor, picazón, sensación de posición y una moderada compresión; concordando esto con Gilbert y Gonzáles ${ }^{24}$ cuando expusieron que el dolor de miembro fantasma, es la sensación dolorosa, que ocurre después de una amputación, referida a la parte distal de la región en que se encontraba previamente la extremidad o en la que se encuentra el muñón que sobresale.

"(...) El dolor que tengo es insoportable, me pica, en mi parte amputada, es como si tuvieras chile, es algo quemante, pero ahí lo tienes no se va, pero trato de controlarlo y en veces si lo logro, aunque la mayor parte del tiempo me delata". (P-09)

El participante confirma las expresiones referente a un dolor fantasma, desconocido, oculto, que en dicho mundo es indescriptible, como expresar sentimientos y emociones, que le recuerdan su vivir con el dolor, al manifestar dolor de miembro fantasma no sólo le duele la parte amputada también le duele el alma.

Siguiendo esta perspectiva tenemos que en la persona postamputada el dolor no es una sensación sino una percepción individual, un significado el cual al interpretarlo como un sentimiento defensivo resulta ser un dolor inexperto e insuficiente, para esto Le Breton ${ }^{21}$ manifiesta que el hombre no es una máquina, ni el dolor un mecanismo: entre éste como herramienta virtual de protección y el primero, existe la ambivalencia y la complejidad de la relación que une al hombre con el mundo.

"(...) Me duele algo que ya no me funciona; día a día vives con el dolor, es tu compañero, es como si le pagaran al dolor por molestarte y sí que lo hace; lo tengo ahí me pica me quema siento hormigas me desespero, es mejor morir". (P-08)

"Te duele algo que no existe", sintetiza lo expresado por los tres participantes ya citados con sus respectivos discursos líneas anteriores, cuando la persona postamputada manifiesta el dolor de miembro fantasma le asigna una identidad propia y una condición en la sociedad, los cuales están devaluados y afectan la existencia de la persona a través de la generación de un "estigma" que afecta su mente como persona. Es ahí donde el dolor de miembro fantasma se alude a una experiencia íntima y particular en la persona, porque ningún dolor es igual a otro dolor. Se podría decir que el dolor no sólo es algo que se experimenta desde la singularidad, sino que es un elemento central en la construcción de toda singularidad. Para esto Le Breton ${ }^{21}$ afirma que ninguna fórmula definitiva podría abarcar la relación íntima del hombre con su dolor, puesto que de hecho todo dolor remite a un sufrimiento y por tanto a un significado y a una intensidad propia del individuo en su singularidad.

"(...) El estar sentado es incómodo, siento mi pie que ya no tengo por sin ningún lado, torcido, muy estirado y con carga en él, me causa dolor en el pecho y en mis brazos y pies, aunque ya no los tengo, duele mucho por las tardes". (P-04)

El participante, dejo entrever la vaguedad en la identificación de lo oculto, que no se muestra, en lo fantasmal, puede ser que afine las percepciones de la persona respecto al dolor fantasmal. Es así como lo fantasmal y la (in)completitud corporal percibida físicamente se sinergizan en dichas percepciones. De allí que el trabajo del cuidado de enfermería se debe dirigir a ayudar a la persona en la superación de dicha (in)completitud, no sólo física sino fundamentalmente personal subjetiva.

Ante esta realidad en su cotidiano la persona postamputada visualiza el dolor como la trama social y cultural que lo impregna e influye en sus conductas y valores, ya que en su vida el cuerpo se vuelve invisible, dócil, su densidad se difumina en la ritualidad social y en la incansable repetición de situaciones cercanas unas con otras, para esto Le Breton ${ }^{21}$ afirma que en el límite de la existencia salen a la luz momentos de dualidad: ciertos complejos provocan en el individuo la impresión

\section{4}

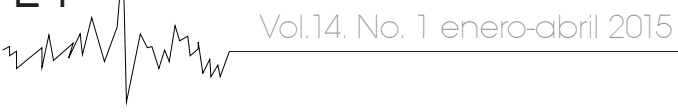


de su indignidad física en relación con los otros, la fatiga, el esfuerzo, una herida, a veces la disparidad entre una voluntad de acción y la imposibilidad de cumplirla; fracasar en el intento de saltar una barrera, nadar o sumergirse, quedarse sin aliento, etc. son hechos que dan la amarga impresión de estar sujeto a un cuerpo diferente del propio indócil en sus realizaciones.

"(...) No estoy completa y para colmo te duele algo que no tienes... te duele en todo momento... siento estirada mi parte amputada, fríos, despiertas con el dolor y duermes con el, si es que logras dormir". (P-10)

"(...) Es feo vivir con el dolor, más como yo estoy, sientes dolor en una parte de tu cuerpo que ya no tienes y eso me llena de rabia, no puedo caminar, me siento incómodo". (P-06)

Al analizar lo discursos anteriores y la relación del hombre con su dolor, éste es no sólo sentir dolor de miembro fantasma, sino que recurre al describirlo como la falta de estética de lo que siente, no existe lógica entre sentir dolor por algo evidente y visible que sentir dolor por algo oculto, invisible, inexistente, un dolor que marca la memoria de la persona

Toda relación de la persona postamputada que presenta dolor de miembro fantasma con su mundo se rompe, el dolor quiebra la unidad vital del hombre con su mundo, la cual es evidente cuando la persona goza de buena salud y confiando en sus fuerzas olvida las raíces físicas de su existencia, cuando ningún obstáculo se interpone entre sus proyectos y el mundo.

Le Breton ${ }^{21}$ expresa que el dolor junto con la muerte es la experiencia humana mejor compartida: ningún privilegio reivindica su ignorancia o su vanagloria de conocerla mejor que cualquiera. Violencia nacida en el propio centro del individuo, su presencia lo desgarra, lo postra, lo disuelve en el abismo que abre en su interior o lo aplasta con el presentimiento de una inmediatez privada de toda perspectiva, evidenciado por el siguiente participante:
"(...) El dolor no es nada bueno en mi cuerpo, me cansa... siento morir, el dolor me enferma y sientes morir, yo siento la muerte a cada momento". (P-11)

En el discurso anterior la persona postamputada con dolor de miembro fantasma dejo entrever cómo su dolor lo vive del todo extraño, rompe sus tramas con las costumbres que instila su persona en el gusto por el vivir y morir. El dolor fuerza su presencia a manera de violación, se sujeta con alfileres en el hombre, haciéndole sospechar el carácter duradero del sufrimiento.

La persona postamputada en su cotidiano vivir al manifestar dolor de miembro fantasma se convierte en esclava de su propio cuerpo, depende completamente de él, padece el peso de su corporeidad, siente su cuerpo como una carga, decadente, debilitado y esto supone el reconocimiento de la propia fragilidad, siente con temor el sufrimiento. Por eso, la corporeidad es mucho más intensa en el dolor que en la salud, porque el dolor lo hace recordar que sigue vivo. Para esto Torralba ${ }^{25}$ manifiesta que en el plano de la estética el ser humano se preocupa por la formalidad de su corporeidad, por la simetría y el equilibrio del mismo y, por otro lado, en el plano de la ética, exige el respeto y la consideración hacia su persona exterior, es decir hacia su corporeidad.

"(...) Mi cuerpo, pues que le digo de mi cuerpo, ahora soy feo, más feo, más disminuido, así vivo cada día, con mi dolor en mi brazo y pierna que ya no tengo". (P-01)

El participante ratifico el componente estético y moral del dolor fantasma, la persona suele manifestar sentimientos de aflicción, manifiesta sentirse rebajado porque la amputación conlleva a una pérdida irreversible y obliga a la persona amputada a acomodarse a una nueva vida con limitaciones físicas.

En el cotidiano vivir de la persona postamputada, las cosas de su mundo se pierden, los sucesos de su vida diaria ya no le importan, pierde toda preo- 
cupación y se hunde en un mundo insignificante, las cosas para él ya no son como antes ni lo serán.

Sciacca ${ }^{26}$ afirma: "El existente acepta su destino" y "coge en la mano su suerte", asume su responsabilidad: vive consciente de no ser nada y acepta su nada. La existencia auténtica es la aceptación del trágico destino, el soportar la angustia hasta sus últimas consecuencias. El que exista "inauténticamente" vive engañado y se niega a aceptar su destino irremediable; en cambio el que vive "verdaderamente" espera sin engaño su destino final.

"(...) Mi vivir es penoso es trágico, tengo pesar con mi vida todos los días siento pena conmigo mismo, me devalúo mucho, con el dolor pierde valor mi vida, más al ver que las demás caminan, algunos pasan corriendo y yo nada". (P-03)

En el discurso anterior se evidencio que la persona postamputada en su cotidiano de vida presenta reacciones emocionales intensas como desprecio y falta de valor hacia su persona las cuales están condicionadas por el dolor que percibe y el grado de incapacidad resultante, lo que conlleva a la añoranza de participar en una deambulación normal. No controla lo fantasmal y la (in) completitud lo lleva a la desvalorización personal, que es un aspecto clave a ser atendido por el cuidado de enfermería en su acompañamiento en el tránsito de quedarse con lo visible sin conexión con lo invisible del dolor en la memoria.

\section{CONSIDERACIONES FINALES}

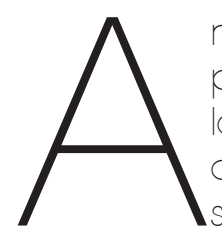
nalizando el vivir con dolor en la persona postamputada confirmamos que el dolor de miembro fantasma es una señal de vida única de cada ser humano, una señal que la persona precisa asumir para escapar de las circunstancias que vive y de la banalidad de su cotidiano, donde no controla la (in) completitud y el dolor fantasmal se hace más evidente; se manifiesta en un vivir cotidiano marcado por reacciones emocionales intensas como sentirse rebajado, aflicción, desprecio y falta de valor hacia su persona, condicionadas por el dolor que percibe y el grado de incapacidad resultante y conlleva a la añoranza de realizar una deambulación normal, además manifiesta signos como comezón, hormigueo, desesperación y se ayuda por expresiones como "me duele y quema al mismo tiempo", "me hormiguea y me da picazón caliente, molesta siempre" y "es como si tuvieras chile", enfatizando lo fantasmal en la mutilación misma, donde existía su pierna, el brazo o aquella parte del cuerpo que ya no tiene. Expresan una vida sin objetivos, se determinan a desempeñar el rol de enfermos al considerar su dolor como una tragedia personal o una desviación social que enluta su vida y la de su familia.

Es así como al profesional de enfermería le corresponde abordar este tema buscando construir proyectos de vida dignos, basados en situaciones que contribuyan al cuidado de la salud en el ambiente hospitalario y de la comunidad. De allí que, la enfermera debe aprender a escuchar el cuerpo enfermo, seguir con atención sus señales y sus expresiones ya sean de alegría, llanto, tristeza, dolor, desagrado, silencio, etc., interpretando lo que trata de comunicar y solicita. La enfermera deberá estar atenta y vigilante procurando que el cuerpo-sujeto alivie el dolor físico y el dolor del alma, que se pueda revertir permanente por el resto de su vida, pues vivir con dolor desde el punto de vista fisiopatológico constituye una crisis circunstancial, eventual y controlable que no sucede igual con la enfermedad del alma. De esta manera, el trabajo del cuidado de enfermería se debe dirigir a ayudar a la persona en la superación de la (in) completitud no sólo física sino fundamentalmente personal subjetiva, que en su cotidiano ayuden a trascender y encontrar el verdadero sentido a su vida como seres que se manifiestan a través del tiempo y movimiento.

\section{6}

IMNVW4w Vol.14. No. 1 enero-abril 2015 


\section{REFERENCIAS BIBLIOGRÁFICAS}

1. Morin E. O método Il: a vida da vida. Publicações Europa-América; 1999.

2. Maturana R, Varela $F$. De máquinas y seres vivos autopsiéis: la organización de lo vivo. Editorial Lúmen; 2003.

3. Ángel NI, Guillén MR Núñez. El dolor de miembro fantasma 1ra parte. (Internet). México: 2014 (Acceso 11 Septiembre 2014). Disponible en: http://www.ametd.org/web/images/revista/Algos\%202014/ALGOS\%20 No\%202-2014.pdf )

4. Maturana R, Carbonell CG. Pacientes amputados: Adaptación psicosocial. Boletín Cientîlco Asociación Chilena de Seguridad. 1999.

5. Calderon F. Programa de acción específico. Atención integral a la salud de las personas con discapacidad. Gobierno de los Estados Unidos Mexicanos. Presidencia de la República Mexicana. 2007-2012.

6. Instituto Nacional de Geografía e informática (INEGI). (Internet). México: 2010 Disponible en: http//www.inegi. org.mx. Recuperado: Diciembre 2012.

7. Weeks SR, Anderson-Barnes VC, Tsao JW. Phantom limb pain: Theories and therapies. Neurologist. 2010; 16:277-86.
8. Flor $H$, Nikolajsen $L$, Staehelin Jensen T. Phantom limb pain: A case of maladaptive CNS plasticity? Nat Rev Neurosci. 2006; 7:873-81.

9. Nikolajsen L, Jensen TS. Phantom limb pain. Br J Anaesth. 2001; 87:107-16.

10. Flor H. Phantom-limb pain: Characteristics, causes, and treatment. Lancet Neurol. 2002; 1:182-9.

11. Chahine $L$, Kanazi $G$. Phantom limb syndrome: $A$ review. Middle East J Anesthesiol. 2007; 19:345-55.

12. Nathanson $M$. Phantom limbs as reported by $S$. Weir Mitchell. Neurology. 1988; 38:504-5.

13. Halbert J, Crotty M, Cameron ID. Evidence for the optimal management of acute and chronic phantom pain: A systematic review. Clin J Pain. 2002; 18:84-92.

14. Nikolajsen $L$, Staehelin Jensen $T$. Phantom limb pain. Curr Rev Pain. 2000; 4:166-70.

15. Minayo M. Investigación Social: Teoría Método y Creatividad. Argentina: Buenos Aires; 2003.

16. Hernandez S, M. Metodologia de la investigación. Editorial McGraw-Hill, México; 2006. 


\section{REFERENCIAS BIBLIOGRÁFICAS}

17. Ibañez J. Nuevos avances en la investigación social: La investigación social de segundo orden. Anthropos Editorial. Barcelona; 1998.

18. Triviños $A$. Introdução às pesquisas em ciências sociais: a pesquisa qualitativa em educação. Editora Atlas. Sâo Paulo; 1987.

19. Minayo M. El desafío del conocimiento: Investigación cualitativa en salud. HUCITEC-ABASCO. San Paulo, Río de Janeiro; 1996.

20. Secretaria de Salud (SS). Reglamento de la Ley General de Salud en Materia de Investigación para la Salud. Secretaria de Salud. México; 1987.

21. Le Breton D. Antropología del dolor. Editorial Seix Barral, S.A. España; 1999.

22. Fernandez A. Las alteraciones del esquema corporal: Herramientas para una teoría de la percepción sensorial. Editoria Pérez Rincón H. Imágenes del cuerpo. Fondo de la Cultura Económica. México; 1994.

23. Pellicer F. Cuando la conciencia corporal se enferma. Departamento de Neurollsiología y Neurociencias. Instituto nacional de Psiquiatría. México. Disponible En: http://redalyc.uaemex.mx/redalyc/pdf/582/58232406. pdf (2002).

24. Gillbert R, Gonzalez MD. Dolor en los miembros fantasma y dolor de muñón. Revista Sociedad Española del Dolor. España; (1996).

25. Torralba F. Antropología del cuidar. Editorial Grafícas Lormo. Barcelona, España; 1998

26. Sciacca M. 2004. Heidegger ₹místico de la nada. Disponible en: http//www.arvo.net/includes/document.php?idDoc $=6918 \&$ IdSEc $=896$. 